\title{
Entre la aldea y los rascacielos: identidad, inmigración y territorialidad indígena urbana en Curitiba, Brasil
}

\author{
Flávio Henrique Silva e Sousa \\ Doctorando en Antropología Social \\ Universidad Autónoma de Madrid \\ fhenrique@hotmail.com
}

Recibido: 2 de junio de 2010

Aceptado: 9 de marzo de 2011

\section{RESUMEN}

El presente artículo, fruto de una investigación etnográfica, tiene como principal objetivo reflexionar sobre un relevante contexto social actual: los pueblos indígenas residentes en centros urbanos latinoamericanos. En este caso específico se ha trabajado con una comunidad indígena localizada en el perímetro urbano de la ciudad de Curitiba, al sur de Brasil. El grupo, compuesto hoy en día por 35 familias de indígenas de las etnias guaraní, kaingang y xetá, se enfrenta a diario con una serie de problemas y cuestiones que conciernen, de una forma general, a las demás comunidades indígenas urbanas latinoamericanas: la manutención y el ejercicio de sus identidades específicas, el acceso y la demarcación de áreas indígenas urbanas, y las técnicas de supervivencia e inserción laboral en las ciudades en que viven. A través de un estudio de caso centrado en tres ejes principales (identidad, territorialidad e inmigración y mercado de trabajo), se analiza la situación actual del grupo mencionado, que puede servir de punto de referencia o de comparación para otros estudios realizados en realidades semejantes.

Palabras Clave: Guaraní, xetá, kaingang, identidad, territorialidad, inmigración, Antropología Urbana.

\section{In Between an Indigenous Village and Skyscrapers: Identity, Immigration and Urban Indigenous Territoriality in Curitiba, Brazil}

\begin{abstract}
The present article is a result of an ethnographic investigation and has as its main objective the reflection upon a present and relevant social context: the indigenous people living in urban centers of Latin America. We have analyzed the current situation of a target group through a case study focused on three main themes: identity, territoriality and immigration and labor market. The target group has been an indigenous community located within the urban area of the city of Curitiba, southern Brazil, actually composed by 35 indigenous families from three different ethnics: Guaraní, Kaingang and Xetá. These ethnic groups are faced daily with a series of problems and issues of concern to most of other indigenous Latin-American urban communities: maintenance and the exercise of their specific identities, access and urban demarcation of indigenous areas, and means of survival and labor integration in the cities where they live. We think this study may serve as a reference and comparison to other case studies of similar realities.
\end{abstract}

Key words: Guaraní, Xetá, Kaingang, identity, territoriality, immigration, Urban Anthropology.

Sumario: 1 . Introducción y contextualización del grupo. 2. Territorialidad indígena urbana. 3. Identidades complejas. 4. Inmigración. 5. Historias de vida. 6. Conclusiones. 7. Referencias bibliográficas. 


\section{Introducción y contextualización del grupo}

Podemos pensar que el espacio urbano no es, a priori, un espacio indígena, por lo menos no lo es en relación al imaginario social sobre tales grupos. En la contemporaneidad los pueblos indígenas siguen sujetos a una gran carga de prejuicios y estereotipos que los localiza en un pasado lejano. Hoy en día los pueblos indígenas están presentes en los más diversos espacios de poder, sea el político, el económico, o el educativo. Vemos que en la actualidad se implementa con gran fuerza y rapidez la apropiación, por parte de los indígenas, de espacios urbanos significativos. Con estas afirmaciones pretendemos subrayar de forma puntual algunas temáticas que abordamos a lo largo de este artículo.

La temática de los pueblos indígenas en espacios urbanos va tomando cada vez más relieve y fuerza en las discusiones referentes a las sociedades complejas contemporáneas. Las afirmaciones del párrafo anterior tienen como objetivo principal la reflexión sobre el hecho de quiénes son estos indígenas y sobre las motivaciones que hacen que los grupos y/o individuos abandonen, de forma permanente o momentánea, sus áreas de origen. Dichas cuestiones pueden tener un sinfín de explicaciones, pero atañen principalmente a las políticas territoriales indígenas, al contacto concreto y simbólico, avasallador, que las etnias tienen con los no indígenas, a los procesos migratorios motivados por la búsqueda de mejores condiciones laborales y educativas, y a la construcción de nuevas identidades.

En el contexto del proceso migratorio, tras analizar algunas realidades específicas se comprueba que no todos los grupos y etnias se relacionan de la misma forma con la ciudad. Dependiendo de las circunstancias, vemos que existen preferencias en relación al tamaño y localización de los centros urbanos de destino. En determinados momentos los grupos migran a pequeñas urbanizaciones cercanas a las áreas indígenas, manteniendo de esta forma una relación más estrecha con sus comunidades. Pero nos encontramos también con desplazamientos que van en dirección a grandes centros urbanos, y que buscan una inserción más o menos permanente en el mercado de trabajo de estas ciudades. Estos son los dos casos principales expuestos por Oscar Espinosa de Rivero al hablar de los desplazamientos de grupos indígenas en dirección a las ciudades en la Amazonia peruana. El autor comenta que en general estas migraciones son de carácter local, pero que al mismo tiempo se percibe un gran incremento de contingentes indígenas que van en dirección a Lima, principalmente por su crecimiento y demanda de mano de obra (Espinosa 2009: 52).

Por otra parte, otra cuestión que debe ser llevada en consideración al tratar del tema es el acceso de jóvenes indígenas a la enseñanza formal. Por un lado, vemos que la inclusión en la enseñanza, principalmente en la secundaria y en la universitaria, es un facilitador para que éstos jóvenes se apropien de las nuevas tecnologías, de los códigos y de los lenguajes no indígenas. Pero por otro, nos encontramos con la dificultad de acceso y con barreras simbólicas que los miembros de los grupos indígenas siguen encontrando para acceder a tales niveles de enseñanza. En las instituciones educativas los jóvenes indígenas tienen que lidiar con una carga brutal de prejuicios todavía existentes en relación a las etnias. 
«La mayoría de estudiantes indígenas siente que son ignorados o discriminados al interior de sus instituciones educativas. Esta discriminación se manifiesta de diversas formas. Es frecuente que sus compañeros y a veces también los profesores se burlen de su acento o de sus costumbres, o les ponen apodos y sobrenombres ofensivos. El resultado final es una creciente falta de autoestima que les lleva muchas veces a desarrollar sentimientos de timidez, inseguridad e inferioridad, así como a la negación y el ocultamiento de su identidad indígena» (Espinosa 2009: 57).

Al igual que Espinosa, Ximenes Ponte, que trabaja en la ciudad brasileña amazónica de Belém, Estado de Pará, comparte la idea de que una de las principales motivaciones que lleva a los pueblos indígenas al espacio urbano está relacionada con las oportunidades educativas, que explican no sólo el desplazamiento sino también la permanencia en las ciudades para que los hijos puedan acceder y dar continuidad a la enseñanza. La autora señala también como causas principales la búsqueda de puestos de trabajo y los conflictos internos que pueden surgir en las aldeas de origen (Ximenes Ponte 2009: 264).

Además de estos factores, debemos tener en cuenta la importancia de asentamientos indígenas en los espacios urbanos, que facilitan y/o impulsan el desplazamiento de nuevos inmigrantes a dichos espacios. La seguridad que puede dar un pariente, amigo, o comunidad étnica abierta, puede ser decisiva a la hora de migrar y para que el proceso sea exitoso. Comprobamos la relevancia que dicho aparato social de recibimiento y acogida del indígena inmigrante tiene en la ciudad de Manaus, en la Amazonia brasileña:

«El análisis del proceso migratorio permitió abordar detalladamente las características de la población que se radica en la ciudad, así como las formas de traslado prevaleciente entre diferentes generaciones de migrantes. Los datos cualitativos obtenidos por medio de historias migratorias y laborales revelaron que los antiguos migrantes lo hicieron de manera independiente y por etapas; los más recientes se desplazaron directamente a Manaus (...). En todos los casos, sin embargo, la solidaridad grupal del movimiento migratorio se manifestó en la intensa activación de las redes sociales tribales de lazos diversos» (Fígoli y Fazito 2009: 81).

Junto a todo ello nos parece interesante analizar un concepto que puede ayudarnos a entender de una forma un poco más amplia la temática indígena en general, y la indígena urbana de una forma específica: los «ángulos ciegos», concepto propuesto por Oscar Calavia. Los «ángulos ciegos» son casos caracterizados como procesos de integración inacabados o abortados por la falta de interés de los órganos públicos, o más bien como un residuo o efectos colaterales de la implantación de programas multiculturales. De esta forma vemos cómo pueden ser nocivas, en muchos sentidos, algunas formas de «integración», bien por la uniformidad creada o diseminada para que los grupos encajen en los requisitos impuestos, bien por la creación de estos residuos o efectos colaterales.

El autor cita a los yaminawa como uno de los grupos indígenas que pueden ser considerados de alguna forma residuos de este proceso. Estos son considerados «indígenas problemáticos». Están localizados en el Estado brasileño amazónico de Acre, en la frontera con Bolivia y Perú. Prescindieron desde hace tiempo de sus pinturas y 
adornos corporales, no celebran sus rituales y dejaron por completo su artesanía. Aun así, su territorio está demarcado desde hace más de quince años. Por diversos motivos, como pueden ser trámites burocráticos, tratamientos médicos, visitas a parientes o llevados por el simple deseo, están siempre viajando. Estos desplazamientos van en dirección a las ciudades cercanas, pero también pueden llegar a la capital, Rio Branco. Tenemos que subrayar que los yaminawa no son inmigrantes, ya que en general no se establecen en los centros urbanos, simplemente viajan.

«En las calles de la ciudad los yaminawa son transeúntes frecuentes, pero inestables. Acaban rápidamente las provisiones que llevan o los recursos con que cuentan. Rara vez desempeñan algún trabajo efímero; se refugian bajo el puente, o construyen abrigos en alguna zona periférica. Las mujeres mendigan, buscan comida entre la basura o eventualmente se prostituyen» (Calavia 2007: 5).

Tarde o temprano vuelven a la aldea. Allí, según el autor, es notoria la desenvoltura con que desarrollan la agricultura y la caza. El caso yaminawa es bastante complejo en cuanto a su identidad, ya que esta no está bien definida, al menos no para nosotros que los vemos desde fuera. No quisieron o no consiguieron tornarse una etnia indígena bajo los moldes multiculturales, pero tampoco dejaron de serlo. Es decir, viven en un vacío de identidad, no están ubicados ni en una parte ni en otra, y a la vez circulan libremente entre estos dos mundos distintos. «Hoy son un problema, porque no se deciden a volverse «indios» y vagabundean por los intersticios de una red de identidades locales, sin preocuparse por sedimentar una identidad propia» (Calavia 2007: 6).

Son muchos, por lo tanto, los puntos que tenemos que llevar en consideración a la hora de analizar la realidad indígena urbana, lo cual incrementa la dificultad y complejidad de trabajar con estos colectivos. En este sentido vemos la importancia que tienen los estudios de caso, ya que sólo a partir de éstos podemos tener una visión relativamente amplia de una pequeña parte de esta realidad.

La comunidad indígena con la cual hemos trabajado se encuentra en esta complicada ubicación simbólica. Está localizada en el perímetro urbano de la ciudad de Curitiba, capital del estado de Paraná, al sur de Brasil. Se trata de una de las zonas más ricas y desarrolladas de Latinoamérica. Curitiba es una ciudad de dimensiones considerables, con aproximadamente 3 millones de habitantes, y es uno de los principales centros políticos y económicos de la zona y del país. Es considerada una ciudad europeizada, tanto por la gran colonización que hubo de europeos del norte, como por los buenos índices de calidad de vida, factores valorados positivamente.

Los miembros de las tres etnias (guaraní, xetá y kaingang) que viven hoy en la aldea Kakané Porã, donde se desarrolló gran parte de nuestra investigación, son originarios de esta zona del país. De las tres etnias, la guaraní es sin duda la que ha acaparado más atención de los estudiosos y sobre la cual existe más literatura. El contacto con los kaingang se produjo a finales del XIX y principios del XX, y estuvo motivado por la expansión de la frontera agrícola producida por el desarrollo y auge del ciclo del café. Y por último, los xetá, que tienen una historia bastante reciente. El grupo, originario del oeste de Paraná, fue «descubierto» también como consecuencia de un plan de colonización y expansión agraria, en este caso motivado por la expansión de los campos de soja. Así, sólo en la década de 1950 empiezan a tener contacto con la 
sociedad nacional, un contacto que se produjo de una forma brutal y avasalladora, y que en pocos años provocó la casi completa desaparición del grupo.

La conquista de un territorio indígena en Curitiba por parte del grupo con el que trabajamos, fue uno de los principales motivadores para su propia formación y constituyó su primera gran reivindicación. El primer intento de conquista del territorio, en 2001, fue la ocupación de un terreno en los márgenes de una de las carreteras de la ciudad. El terreno era una propiedad privada, y la institución propietaria inició una acción judicial contra el grupo, que acabaría ganando y retomando con ello la zona. El grupo, formado básicamente por las familias de Carlos, Jovina y Alcindo, tres de los principales líderes de la comunidad, tuvo que dejar el área después de ocho meses en el que ellos mismos denominaban «campamento del peaje».

Después de la salida del grupo y tras una desarticulación momentánea, se produce el segundo intento de conquista de la tierra. Esta vez las familias ocupan una pequeña parte de una reserva biológica que se encuentra bajo la responsabilidad del Ayuntamiento de la ciudad, el Parque Iguaçu ${ }^{1}$. Allí fundaron la aldea Cambuhy, donde el grupo permaneció durante casi siete años.

Desde el principio el Ayuntamiento de Curitiba pidió la salida de los indígenas del terreno, alegando que se trataba de un área de protección ambiental. A partir de aquí comienza una larga negociación con el poder público para la construcción de la nueva aldea.

Después de años de reuniones y negociaciones, en diciembre del 2008 la comunidad se traslada a la aldea Kakané Porã, construida en un terreno del Ayuntamiento elegido junto a la comunidad y totalmente financiado por la propia Administración de Curitiba.

En la aldea Kakané Porã viven hoy las 18 familias que vivían en Cambuhy y 17 más que estaban distribuidas por los barrios periféricos de la ciudad.

\section{Territorialidad indígena urbana}

La territorialidad aparece como un elemento fundamental para poder entender el surgimiento y desarrollo del grupo con el que trabajamos, ya que la búsqueda del territorio fue decisiva para la propia formación y consolidación de la comunidad. Para poder entender esta cuestión, partimos de una afirmación que puede parecer obvia, pero que nos parece importante señalar en este momento: el surgimiento de un área indígena no se produce al azar. Así, Cambuhy/Kakané Porã es el resultado de un duro y largo proceso al que se enfrentaron muchos de los miembros que viven hoy en la comunidad.

Por otra parte, la aparición de un área indígena urbana es un fenómeno bastante característico y localizado en la modernidad, que, como los demás fenómenos sociales contemporáneos, tiene una carga de complejidad relevante y de difícil aprehensión. El grupo se enfrentó y se enfrenta a cuestiones muy delicadas referentes al acceso

\footnotetext{
${ }^{1}$ Hemos preferido dejar los nombres propios, de lugar y de personas, en la forma original.
} 


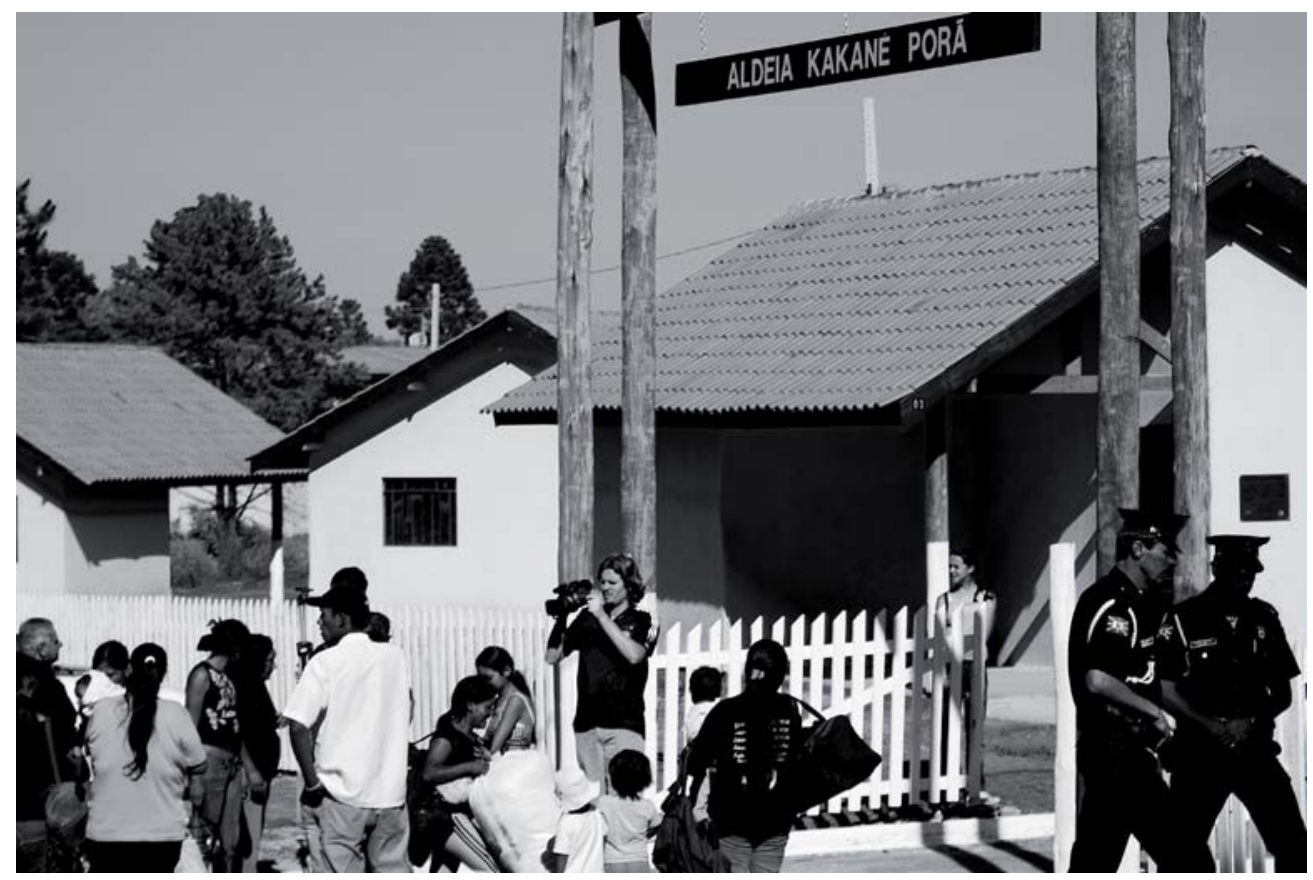

Figura 1: Entrada de la aldea en el día de la mudanza del grupo a Kakané Porã (diciembre de 2008).

a la tierra, principalmente por su particular situación y por su reivindicación de un territorio indígena dentro del perímetro urbano. La cuestión de dichas áreas, por tratarse de una realidad relativamente nueva, es de difícil manejo, y las legislaciones y órganos de gestión y «protección» de los pueblos indígenas todavía no han alcanzado la mejor forma de afrontar esta realidad. A la vez, se trata de un fenómeno cada vez más recurrente en la modernidad, con una relación directa con la aparente necesidad de los pueblos en general y de los individuos en particular, de migrar de sus áreas originales en dirección a los centros urbanos. Una vez instalados en las ciudades surge la inminente necesidad de la composición de un territorio indígena, necesidad motivada tanto por cuestiones económicas como por cuestiones relativas a la manutención de las costumbres y rituales propios.

Para poder centrarnos con bases más sólidas en el caso específico de la comunidad estudiada, nos es necesario examinar algunas cuestiones relativas a la posesión y al disfrute de la tierra. Se trata, sin duda, de uno de los temas más importantes para gran parte de los pueblos indígenas contemporáneos. La tierra, el acceso, la posesión y el disfrute de la misma, son el primer paso en dirección a la manutención y ritualización de las culturas indígenas latinoamericanas. Es ésta una relación que forma parte del universo mítico de estos pueblos.

García Hierro (2001) distingue dos formas básicas de relacionarse con la tierra: una en la que ésta es percibida como propiedad privada, económica (sociedades oc- 


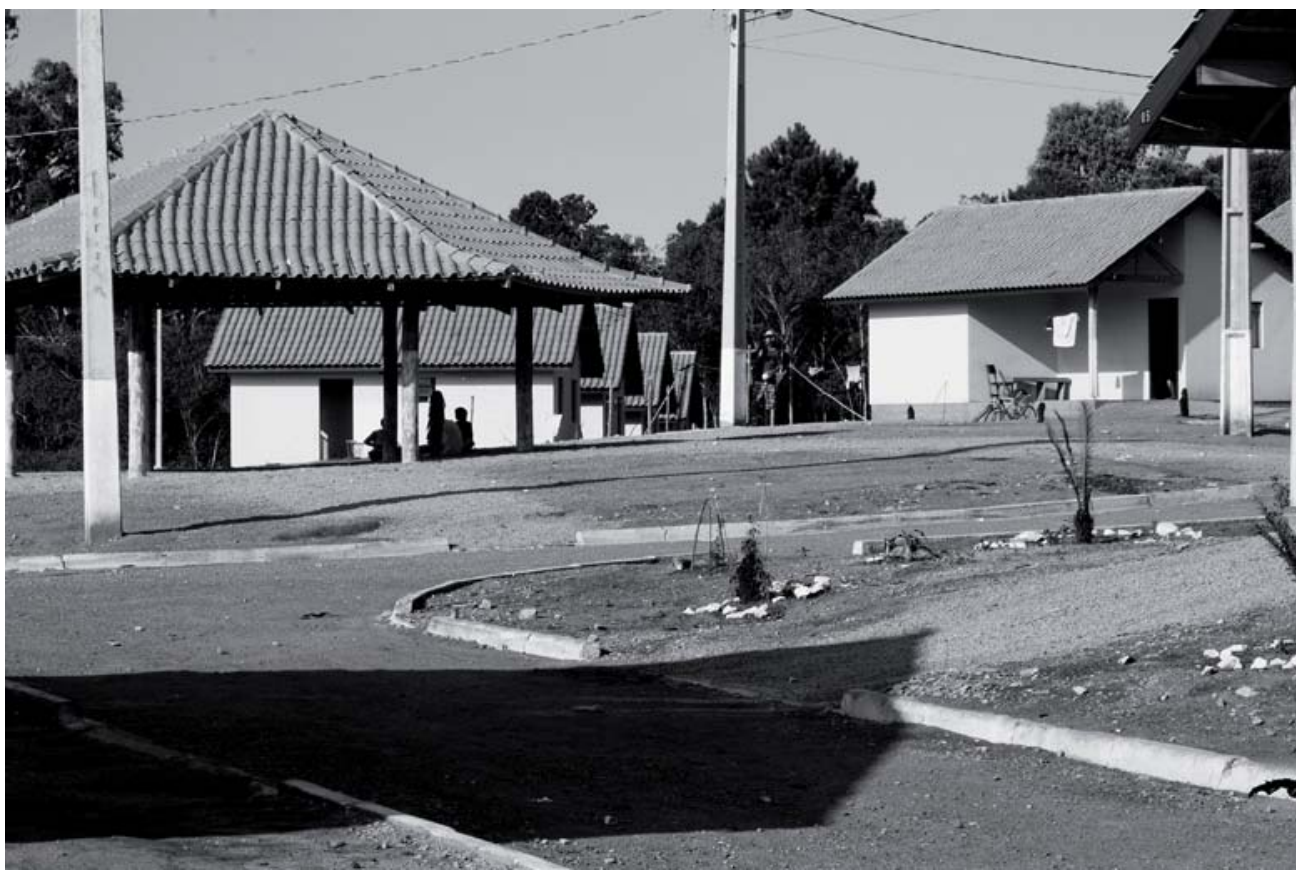

Figura 2: Vista general de la aldea. Grupo de niños ocupando el patio central (marzo de 2009).

cidentales), y otra en la que es vista como propiedad colectiva, política (pueblos indígenas).

La relación de los pueblos indígenas con sus territorios es colectiva, no existe la dimensión privada de la finca o de la casa como la conocemos nosotros. Para ellos, la tierra de determinado grupo es un bien común, indivisible, que debe ser trasmitido generación tras generación.

«En el caso occidental la propiedad de la tierra es un derecho civil y corresponde a un individuo. En el caso de las sociedades indígenas la cuestión de la tierra es diferente; el territorio se vincula más bien al pueblo que al individuo y nadie piensa que puede disponer de él a su antojo. Algo parecido puede decirse del territorio de Bolivia, por ejemplo. Es del pueblo boliviano pero no parece correcto decir que es propiedad civil de Bolivia ni mucho menos de ninguno de sus ciudadanos (a pesar de que, de acuerdo con sus normas internas, cada lugar concreto de Bolivia esté vinculado jurídicamente a un individuo, o pueblo, o comunidad concretos). Bolivia, el pueblo o sus representantes, no podría vender su territorio nacional o parte de él porque dejaría de ser Bolivia. Así, cuando hablamos del territorio de Bolivia estamos hablando de un derecho político (que se respeta por otros pueblos) y no de un derecho civil (que se debe respetar entre los particulares que viven dentro de Bolivia). 


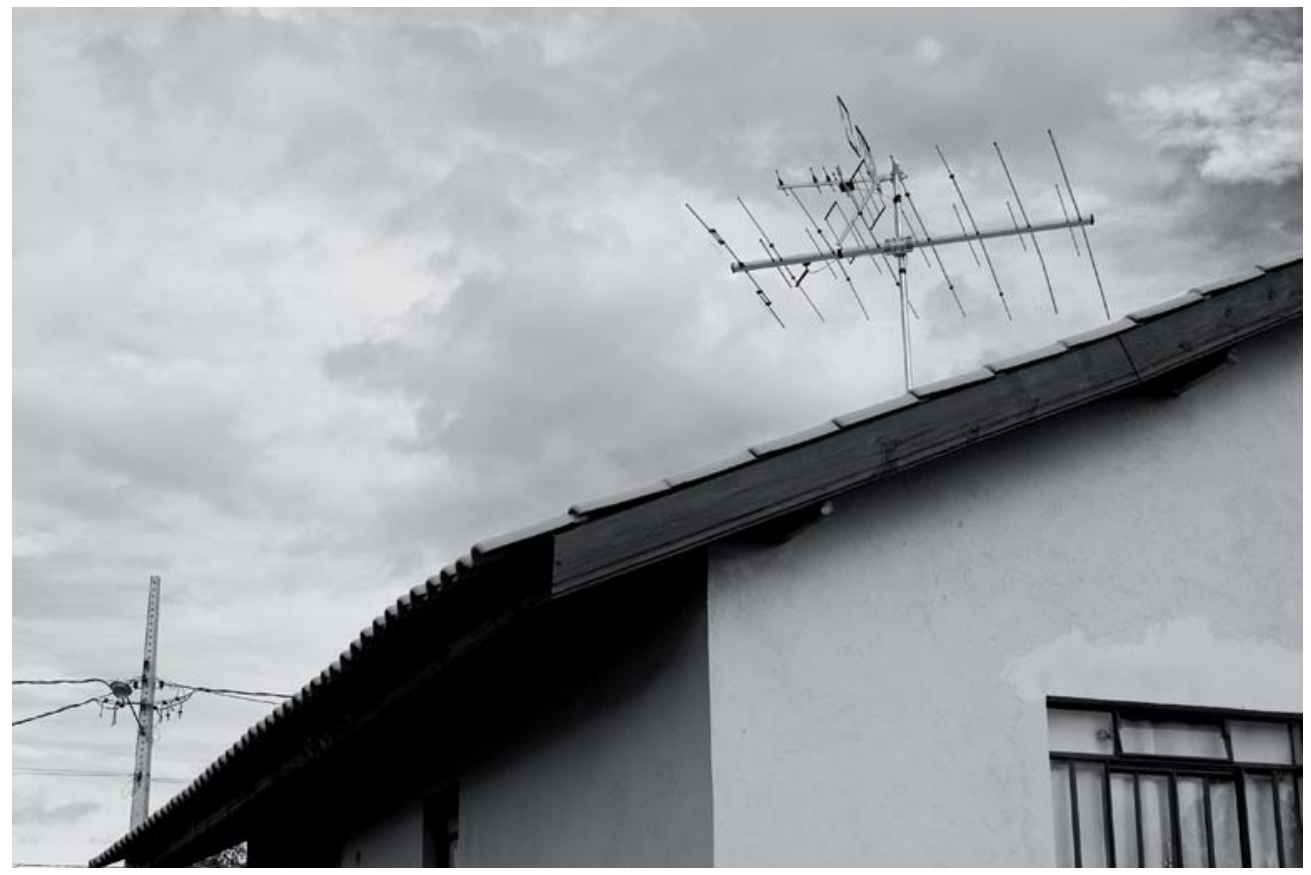

Figura 3: Detalle de una de las casas de la comunidad. Las familias empiezan a apropiarse del lugar y a modificar los espacios (marzo de 2009).

Para los pueblos indígenas, el territorio corresponde más bien a ese concepto de derecho político que al concepto que emana del derecho civil, al margen de cómo se regule la tenencia de tierras a nivel interno cada pueblo necesita que desde el exterior se respete su territorio íntegramente» (García Hierro 2001: 622-623).

Cuando hablamos de territorialidad surge una cuestión que no puede disociarse del tema del usufructo de la tierra: la autonomía del territorio. La idea de territorio es la de un espacio no disponible, inapropiable y autónomo en su gestión, donde el pueblo que allí vive tiene totales poderes para hacer lo que le conviene. Tal prerrogativa es conflictiva cuando hablamos de territorios indígenas, pues éstos se encuentran inseridos dentro de contextos nacionales específicos que son a su vez territorios autónomos e indivisibles.

De acuerdo con la Constitución Brasileña que regula los territorios indígenas, las tierras les son concedidas de forma permanente. Pero la autonomía de las áreas indígenas no es total, puesto que están dentro de algo mayor, de un Estado Nacional, del que depende dicha autonomía. Este es uno de los principales motivos de conflicto con los órganos que administran las cuestiones indígenas.

Dada la complejidad de la situación específica del grupo que compone Kakané Porã, el proceso legal del surgimiento de la aldea fue bastante distinto del procedimiento habitual para las homologaciones de áreas indígenas en Brasil. Por tratarse de 
un área urbana y de una ocupación relativamente reciente dado el carácter inmigrante de sus miembros, sería complicado aplicar la normativa vigente para caracterizar y demarcar un territorio que pudiera ser destinado para el establecimiento del área indígena en la ciudad de Curitiba. En principio sería difícil justificar la ocupación tradicional indígena en la ciudad, factor de gran relevancia para el proceso de demarcación de tierras. La ocupación indígena de Curitiba existió de forma efectiva, pero esta relación se ha perdido en el tiempo, y se siente hoy como algo lejano. Así, en la actualidad, pertenece únicamente al universo mítico de los pueblos indígenas. Los guaraní, por ejemplo, tienen una relación mitológica muy cercana con la Sierra del

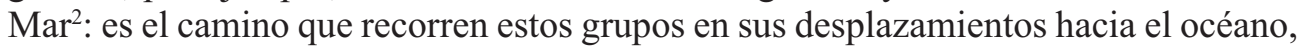
«la gran agua». En la propia narrativa mitológica guaraní podemos ver cómo dos de las ciudades más importantes de Paraná están localizadas en su universo semántico:

«Então começou a caminhada para a beirada do oceano. E foram fundando vários lugares para depois «serem cidades» (tetã). Passaram em Kuriyty (Curitiba) e pararam algum tempo. Ali se separaram. Alguns desceram pelo mato, em direção ao mar, à procura de seu lugar. E encontraram Opavãpy ou Iparavãpy (Paranaguá)» (Ladeira 2007: 144).

Partiendo de la casi imposibilidad de conquista territorial del grupo a través del modelo «tradicional» contemplado por la legislación de demarcación de tierras indígenas, el grupo trazó otras estrategias para alcanzar sus objetivos.

Como hemos dicho anteriormente, la comunidad ocupó un determinado terreno que les parecía interesante para la permanencia en la ciudad. El área ocupada en 2002 en la Avenida das Torres es gestionada por el Ayuntamiento de Curitiba y forma parte del complejo ambiental del Parque Iguaçu. Según el cacique Carlos, desde el primer momento el Ayuntamiento reivindicó la posesión del terreno que correspondía a la aldea Cambuhy.

Desde el principio de las negociaciones para la salida del grupo del área de protección ambiental, la Administración les ofreció el local donde hoy se encuentra la nueva aldea (Figura 1). El terreno está localizado en la periferia de la ciudad y se trata de un lugar mucho menos central que la antigua aldea, pero aun así la oferta parecía interesante puesto que las condiciones de vivienda encontradas en Cambuhy eran bastante precarias.

La aldea actual tiene un área aproximada de $44.000 \mathrm{~m}^{2}$ (Figura 2). En ella se invirtieron alrededor de 705.000 reales (unos 250.000 euros) y fue idealizada y construida por la COHAB-Curitiba (Compañía de Habitación Popular de la Ciudad de Curitiba) (Figura 3).

La dimensión de la aldea también influye en aspectos tradicionales tanto para los kaingang como para los guaraní. Los kaingang, por ejemplo, tienen una relación muy cercana con la muerte, y uno de los principales rituales de este pueblo es la fiesta del Kikikoi ${ }^{3}$. El

\footnotetext{
2 Nombre del conjunto montañoso donde se encuentra la ciudad de Curitiba. Se extiende desde el Estado de Espírito Santo (Sudeste) hasta Santa Catarina (región Sur), bordeando el litoral de toda esta zona.

3 Se trata de un ritual que no se practica en la mayoría de las aldeas kaingang, y que tampoco es realizado en Kakané Porã.
} 
ritual consiste en un homenaje a los muertos recientes organizado por sus parientes consanguíneos y sirve para guiar a los espíritus en su nuevo mundo y para cerrar la relación de éstos con el mundo terrenal kaingang. Tiene, así, como objetivo, armonizar los dos mundos, el mundo de los vivos y el de los muertos. En general los indígenas kaingang son enterrados en sus áreas de origen, donde su ombligo fue enterrado al nacer. Cuando le pregunto al cacique Carlos si los indígenas kaingang nacidos en Kakané Porã un día podrán ser enterrados allí, me contesta que no, ya que el área es muy pequeña para que pueda ser construido un cementerio, de forma que los indígenas de Kakané Porã deberán ser enterrados en «las aldeas grandes» donde todavía tengan parientes.

Lo mismo ocurre con los guaraní. Éstos tienen una relación muy cercana con la religiosidad. La casa de oración guaraní es un espacio donde acontecen rituales constantemente, y es un elemento primordial para entender y ejercer la identidad guaraní. Hablando con los guaraníes que viven en Kakané Porã, me hablan de la dificultad que supondría encontrar un espacio adecuado en la aldea para la construcción de la Casa de Reza.

Tanto la mitología guaraní como la kaingang tienen una estrecha relación con el territorio. El matão, la floresta kaingang, está repleto de significados cosmológicos. De la floresta vienen las yerbas y medicamentos necesarios para la vida cotidiana. Además, también procede de ella el poder del Kuiã (chamán kaingang) que a partir de su interacción con la floresta relaciona el mundo terrenal con el espiritual. Gran parte de sus nombres propios vienen del matão, al igual que la pintura corporal utilizada en los rituales, que es extraída del carbón mezclado con determinadas yerbas y que cambia de acuerdo con la mitad Kamé o Kairu ${ }^{4}$ a la cual pertenecen los miembros (Baptista da Silva 2002: 195-196).

Entre los guaraní también está presente esta relación con los territorios y la floresta. En sus narrativas míticas aparecen diversos momentos de construcción, destrucción y reconstrucción del mundo, teniendo siempre como centro al pueblo guaraní. Este universo comprende como territorio la amplia zona que va desde Paraguay, pasando por el norte argentino y uruguayo y el sur de Brasil. Según ellos, el mundo fue hecho para todos por Nhanderu, el Padre, el Creador de todo (Ladeira 2007: 144).

En ese sentido, la aldea Cambuhy era un espacio mucho más adecuado para la manutención de las cuestiones rituales relacionadas con la naturaleza, ya que disponían de una gran zona verde. La falta de bosque nativo y de tierra, influye tanto en estas cuestiones rituales como en las económicas, ya que del bosque procede la madera, las fibras y las semillas necesarias para la producción de artesanía, tanto guaraní como kaingang. Además, las plantaciones familiares son inviables dado el tamaño de la aldea actual.

\section{Identidades complejas}

Hablar de identidad supone entrar en un campo de discusión amplio y abierto. El estudio y reflexión sobre este tema en las sociedades contemporáneas nos muestra la dificultad de comprensión de dicha realidad y su gran complejidad.

${ }^{4}$ El mundo kaingang está dividido en dos mitades complementarias, Kamé y Kairu. Todo el universo pertenece a una de esas dos mitades. 
Por estar dentro del campo subjetivo, no palpable, y muchas veces de difícil visualización, percepción y acercamiento, nos encontramos, nosotros antropólogos y otros científicos sociales, en un callejón casi sin salida, pues dada la delicadeza del tema, no es fácil seguir una línea de pensamiento clara y coherente.

Por otra parte, la complejidad del contexto actual es un generador de nuevas identidades, consecuencia de una mezcla entre la retomada y reafirmación de saberes locales, tradicionales, relacionados con una amplitud de fenómenos de difícil entendimiento, generados y desarrollados con la globalización. Así, vemos surgir a personas y grupos cada vez más complejos, con identidades híbridas, identidades que son a la vez tradicionales y modernas, urbanas y rurales, que pertenecen tanto al pasado como al presente, y que, principalmente, poseen la capacidad de desplazamiento entre distintos mundos que, para un observador no muy atento, parecen contradictorios y no complementarios.

No pretendemos aquí hacer una reflexión profunda sobre el tema, sino utilizar la discusión ya hecha por científicos relevantes y, a partir de ella, analizar el caso específico de la aldea Cambuhy/Kakané Porã.

En primer lugar plantearemos un concepto de identidad que consideramos interesante y que tomamos prestado de Castells para que nos sirva de guión. Según el autor:

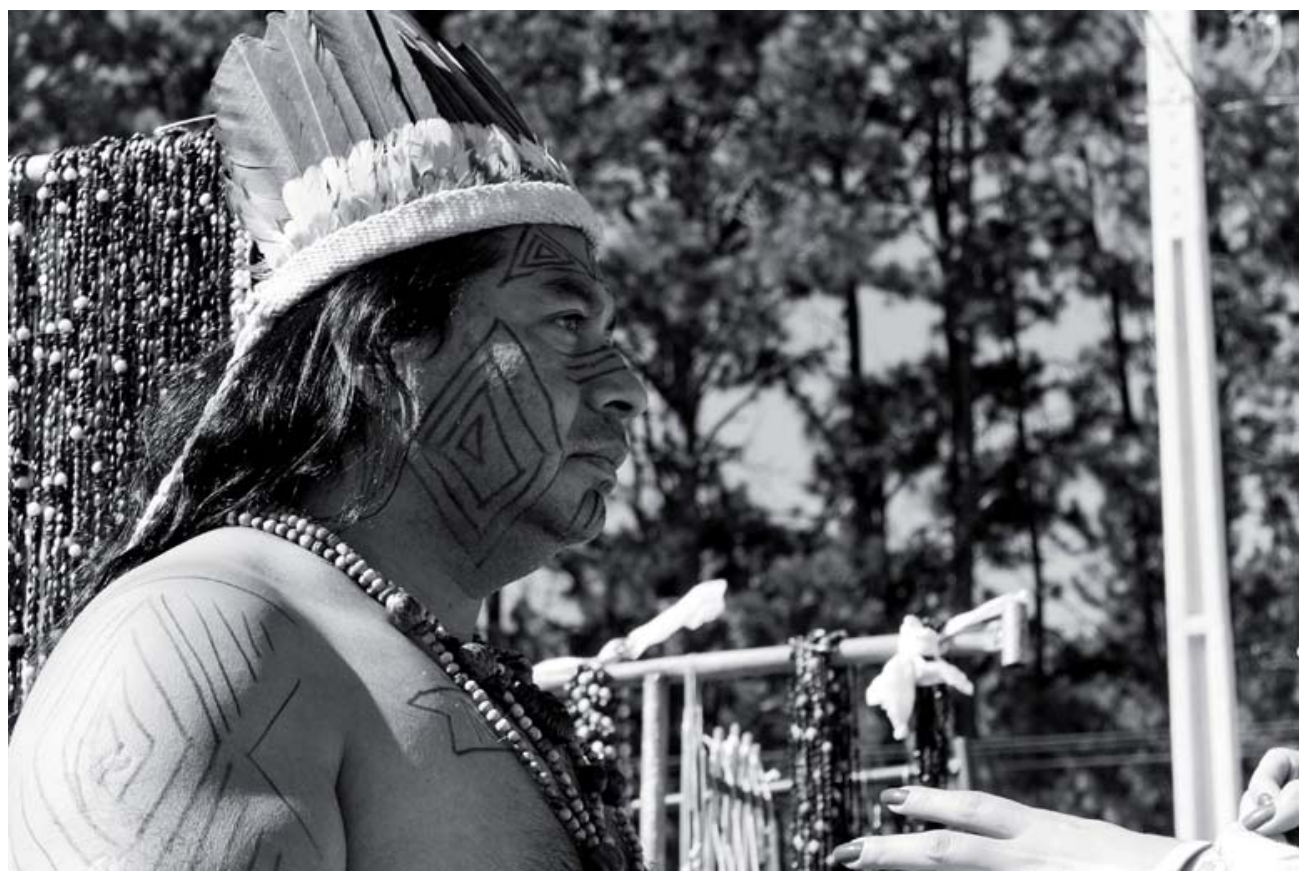

Figura 4: El cacique Carlos en una entrevista concedida a los medios de comunicación locales en la inauguración de la aldea Kakané Porã (abril de 2009). 
«No que diz respeito aos atores sociais, entendo por identidade o processo de construção do significado com base num atributo cultural, ou ainda um conjunto de atributos culturais inter-relacionados, o(s) qual(ais) prevalece $(\mathrm{m})$ sobre outras formas de significado. Para um dado indivíduo ou ainda um ator coletivo, podem haver identidades múltiplas» (Castells 2000: 3).

Para Castells, la identidad funciona como una base para significar el mundo, para entender lo que sucede alrededor. Tiene su origen en la cultura y es reproducida, modificada y resignificada a través de ella. Es un juego de ida y vuelta, dialéctico, capaz de dar sentido al mundo, de interpretarlo, y, a partir de tales interpretaciones, relacionarse con él.

La identidad no la construyen personas, no proviene de un único individuo que establece reglas e impone cómo debe ser significada la realidad, sino que procede de una construcción colectiva muy anterior de los que ahora se apropian de ella. «Entende-se por identidade a fonte de significado e experiência de um povo» (Castells 2000: 2). Es una construcción y propiedad colectiva que está al mismo nivel subjetivo y colectivo que el imaginario o que la cultura. Se trata de una construcción donde no podemos identificar claramente el origen y que está al servicio de toda una comunidad, de toda la colectividad.

La idea de una identidad colectiva nos proporciona a los antropólogos el estudio de tal fenómeno en el ámbito de los grupos sociales. Los estudios hechos a partir de la

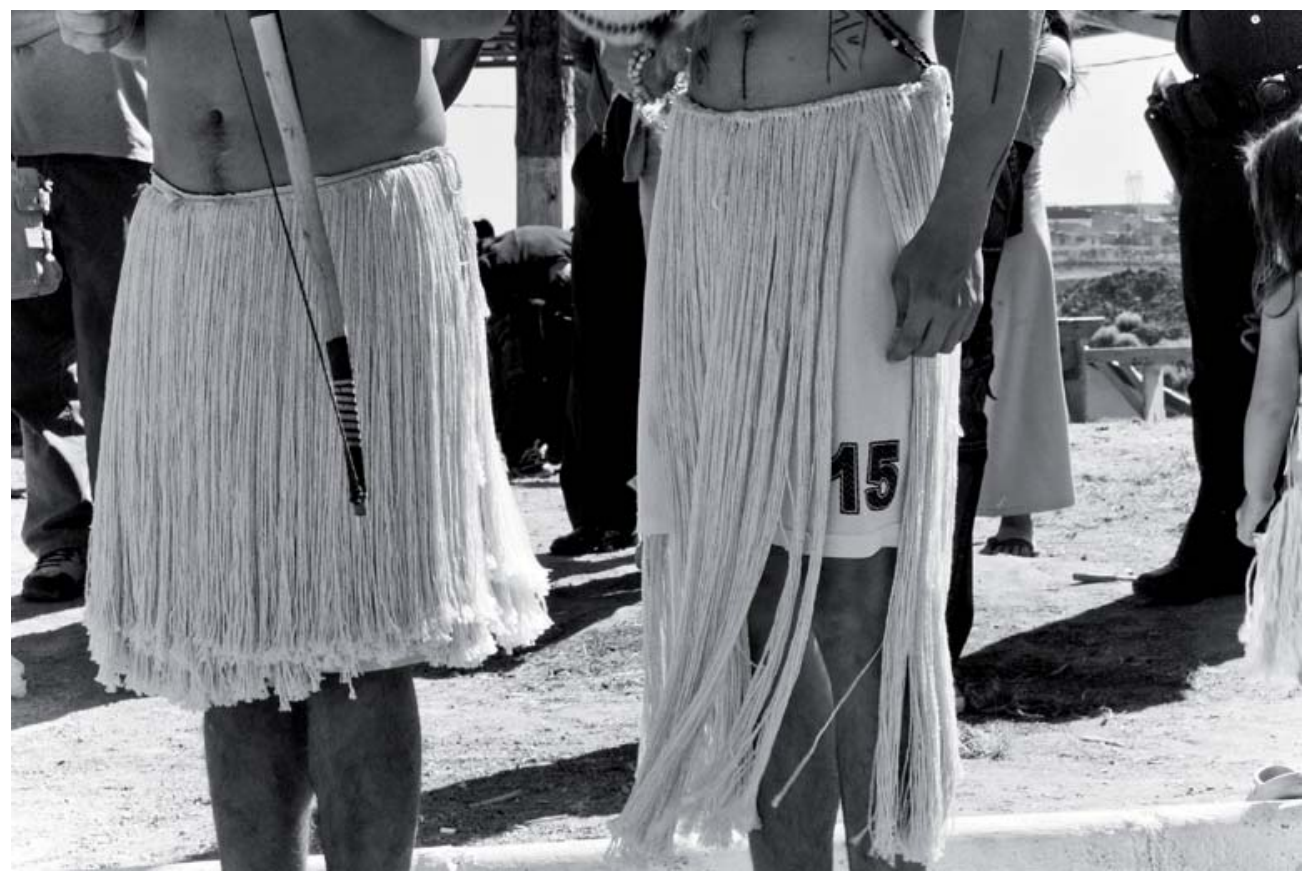

Figura 5: Jóvenes de la comunidad en una presentación de música y danza en la aldea Kakané Porã (abril de 2009). 
identidad nos hacen reflexionar sobre las más distintas realidades como por ejemplo los movimientos feministas, las nuevas identidades juveniles o el proceso migratorio actual. Nos permite también enfocar el tema que queremos tratar ahora: la formación de nuevas identidades indígenas en el contexto de la globalización.

Para comprender el fenómeno por el que pasa la comunidad de Kakané Porã, fenómeno al mismo tiempo específico y general, es interesante pensar también en el concepto de «identidad contrastiva» que Roberto Cardoso de Oliveira recoge:

"A identidade contrastiva parece se construir na essência da identidade étnica, à base da qual esta se define. Implica a afirmação do nós diante dos outros. Quando uma pessoa ou grupo se afirma como tais, o fazem como meio de diferenciação em relação a alguma pessoa ou grupo com quem se defrontam. É uma identidade que surge por oposição. Ela não se afirma isoladamente» (Cardoso de Oliveira 1976: 6).

En el caso de la identidad étnica, una de las formas de identidad colectiva, la autoafirmación, el nosotros, necesita un punto de referencia para reconocerse: el otro. Cuando los valores son afirmados es necesario un referente para hacer las debidas comparaciones. Es decir, un determinado grupo siempre se afirma en relación a otro, hecho que según Cardoso de Oliveira crea una relación etnocéntrica, donde los valores de determinado grupo están por encima de los valores de otro.

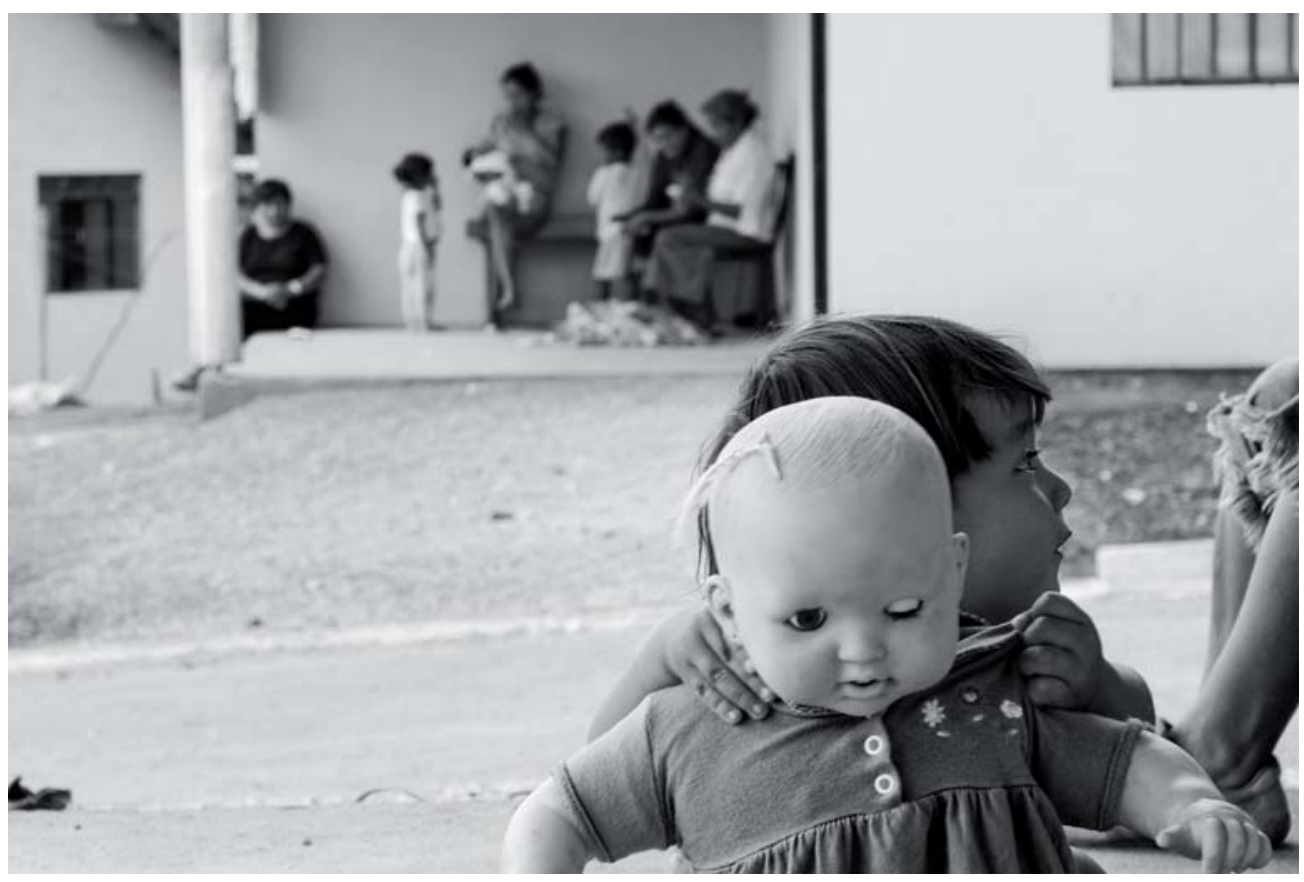

Figura 6: Niño guaraní jugando con sus muñecos (marzo de 2009). 
Identificarse o formar parte de determinado grupo, a priori, conlleva también ser identificado con algo. A partir de eso, los miembros de algunos grupos pueden ser víctimas de estereotipos, prejuicios y discriminación por parte de otros grupos sociales. En el caso concreto de los indígenas, éstos sufren una carga inmensa de estereotipos negativos en el contacto con el mundo blanco. «Los indígenas han sido siempre víctimas del racismo y la discriminación por parte de la población no indígena, las instituciones sociales y el Estado» (Stavenhagen 2002: 2).

Para continuar con la reflexión es importante pensar también en el concepto de identidades híbridas. Éstas pueden ser vistas como una forma de interacción entre individuos o grupos distintos que por habitar o estar en un determinado espacio, que en principio puede que no sea el «suyo», entran en contacto con otras formas de relaciones sociales, con identidades distintas a la suya, es decir, con otra forma de interpretar el mundo. La hibridez de individuos, grupos y comportamientos, que puede ser generada por este contacto, nos hace pensar en las cuestiones relacionadas con el contacto interétnico.

El espacio urbano contemporáneo es un gran generador de culturas, identidades e individuos híbridos. Los avances tecnológicos en el área de los transportes, las telecomunicaciones y la industria en general, los nuevos patrones de consumo y la resignificación de valores encontrados en nuestra época, nos lleva a encarar al individuo urbano, rico en complejidad, al mismo tiempo como uno y otro. Lo que queremos decir es que el espacio urbano contemporáneo, visto y analizado a partir de reflexiones que lleven en consideración las diferencias, que de alguna forma crean la unidad, es un espacio privilegiado de interacción entre las más diversas formas de comportamientos, ideologías y cosmovisiones. Las ciudades, ya sean grandes o pequeñas, centrales o periféricas, ricas o pobres, bien o mal comunicadas, son espacios ricos en términos de interacción, expresión, intercambio de experiencias y relaciones interétnicas.

El boom tecnológico ocurrido en el siglo XX impulsó, en muchos sentidos, este proceso de hibridismo de las ciudades, pueblos e identidades. En el caso específico de Latinoamérica, el proceso migratorio vivido en las últimas décadas contribuyó fuertemente a la hibridez cultural vista hoy en las grandes ciudades. Latinoamérica pasa de tener al principio del siglo XX aproximadamente $10 \%$ de su población viviendo en zonas urbanas, a un 60 o 70\% en los días de hoy. Vemos el cambio de un espacio de interacción relativamente homogéneo, con poco contacto con los centros urbanos, donde gran parte de las comunidades rurales están compuestas por indígenas que viven de forma tradicional manteniendo sus hábitos y costumbres, a un espacio completamente distinto, la ciudad. El cambio, principalmente ocasionado por las nuevas tecnologías implantadas en el campo, junto a la necesidad de mano de obra en la industria y en los servicios de las ciudades, hace que las comunidades rurales emigren a los centros urbanos en busca de trabajo y renta. En la ciudad, estos individuos «homogéneos», venidos del campo, encuentran un panorama extremadamente heterogéneo y dinámico, que mantiene una constante interacción de lo local con lo global, lo que caracteriza un dinamismo de símbolos y significados que es nuevo para las comunidades rurales inmigrantes (García Canclini 2003: 285). 
En el contexto urbano contemporáneo, esta toma y apropiación de códigos y conductas es casi una necesidad para la inserción/manutención de la vida en la ciudad. Esta inserción/manutención genera nuevas narrativas de la identidad, que a su vez son un espejo de estas nuevas y diversas formas de relacionarse con el mundo, este mundo globalizado y lleno de sutilezas en su cotidianidad (Agier 2001).

La situación particular de la aldea Kakané Porã tiene sus especificidades por tratarse de una comunidad indígena establecida en una ciudad de dimensiones considerables como es Curitiba. Aunque algunos de los miembros lleven muchos años en la ciudad, mantengan poco contacto con otras áreas, o no realicen algunos de los rituales importantes para sus etnias, vemos que la identidad indígena sigue estando muy presente en el día a día de la comunidad, y que sigue siendo reafirmada principalmente en el campo del discurso.

Aun teniendo en cuenta la diferenciación que ellos mismos establecen entre el indígena del campo y el indígena de la ciudad, todos coinciden en un punto: la autoidentificación como indígenas (Figura 4).

Durante la observación de campo y de acuerdo con las entrevistas realizadas, en todo momento y con todos ellos quedó claro que se trata de un área indígena, habitada por indígenas. Cuando se les preguntó directamente sobre el tema, contestaron así: «Claro, claro, soy indígena» (risas), «Sí, de la etnia guaraní», «Sí, soy xetá. Mi padre era xetá. Mi madre kaingang, pero mi padre era xetá.», «Sí, soy guaraní, mis padres son guaraní», «Sí, sí, soy kaingang».

El ser indígena es algo que no se cuestiona, al menos no internamente. La cohesión del grupo hace que cualquier tipo de duda en relación a eso sea completamente infundada, incluso cuando la transmisión de la etnicidad a través del parentesco es interrumpida a lo largo de las generaciones. Tanto en el caso kaingang como en el guaraní y el xetá, la pertenencia étnica es transmitida a través del hombre: la etnicidad de éste determina la de su prole. Es decir, un hijo de hombre kaingang va a ser kaingang, pero no necesariamente un hijo de una mujer kaingang es kaingang. Los matrimonios interétnicos son cada vez más frecuentes, indígenas que forman familias con no indígenas o con indígenas de otra etnia, y que tienen hijos que deberían ser, pero que no necesariamente son, indígenas mestizos o no indígenas.

Para ilustrar este tema traemos el caso de Valdinei. Ésta vino a Curitiba muy joven, $\mathrm{y}$, como gran parte de los indígenas que viven en la comunidad, con la perspectiva de mejoras en la calidad de vida, empleo y renta. Estuvo trabajando durante mucho tiempo como niñera y en trabajos domésticos en la ciudad. Ya no tiene mucho contacto con su área original porque gran parte de sus parientes fallecieron. Valdinei tiene unos cincuenta años. Tuvo a su hija con un no indígena que conoció en un área del Estado de Santa Catarina, provincia vecina de Paraná. Allí estuvo viviendo algunos meses con el padre de su hija, pero luego se separó y volvió a Curitiba.

Cuando le pregunté a Valdinei si era indígena me contestó, al igual que los otros interlocutores, afirmando sin ningún tipo de dudas que sí lo es. Entonces profundicé un poco más preguntándole sobre su hija y su nieta de dos años. Su hija, a partir de la tradición kaingang, es mestiza, ya que como es hija de no indígena no hereda la 
marca étnica. Pero me dice que su hija sí se considera indígena, y que ella, Valdinei, también la considera así.

Vemos así cómo en Kakané Porã la propia pertenencia étnica ha tomado dimensiones simbólicas híbridas: la pertenencia al grupo étnico ya no es solamente atribuida a través de la tradición, sino a partir de elementos subjetivos y abstractos que también forman parte de esta nueva cosmovisión forjada en la comunidad.

En el caso de Valdinei la pertenencia étnica «legítima» (tradicional) ha vuelto a su familia: su nieta es hija de «mestiza» (su hija) con indígena kaingang, por lo que ésta, naturalmente, lleva consigo el origen del padre. Una «pérdida» y retomada étnica, en los modelos tradicionales, al grupo kaingang. Volviendo a la entrevista, cuando le pregunto si su hija es indígena me contesta: «Ella es mestiza (...). Pero ella se considera indígena, y yo la considero indígena, así como a la bebé, su padre es indígena kaingang». Vemos así que Valdinei lleva en consideración dos formas de manutención e inclusión en el grupo: una a través de la autoidentificación, como acontece con su hija, y otra mediante la forma tradicional de inclusión y transmisión étnica, la del parentesco. Según parece, al menos en este caso específico, no existe ninguna contradicción o conflicto: las dos formas de ser indígena parecen ser legítimas en el universo semántico de Valdinei en particular, y de la comunidad en general.

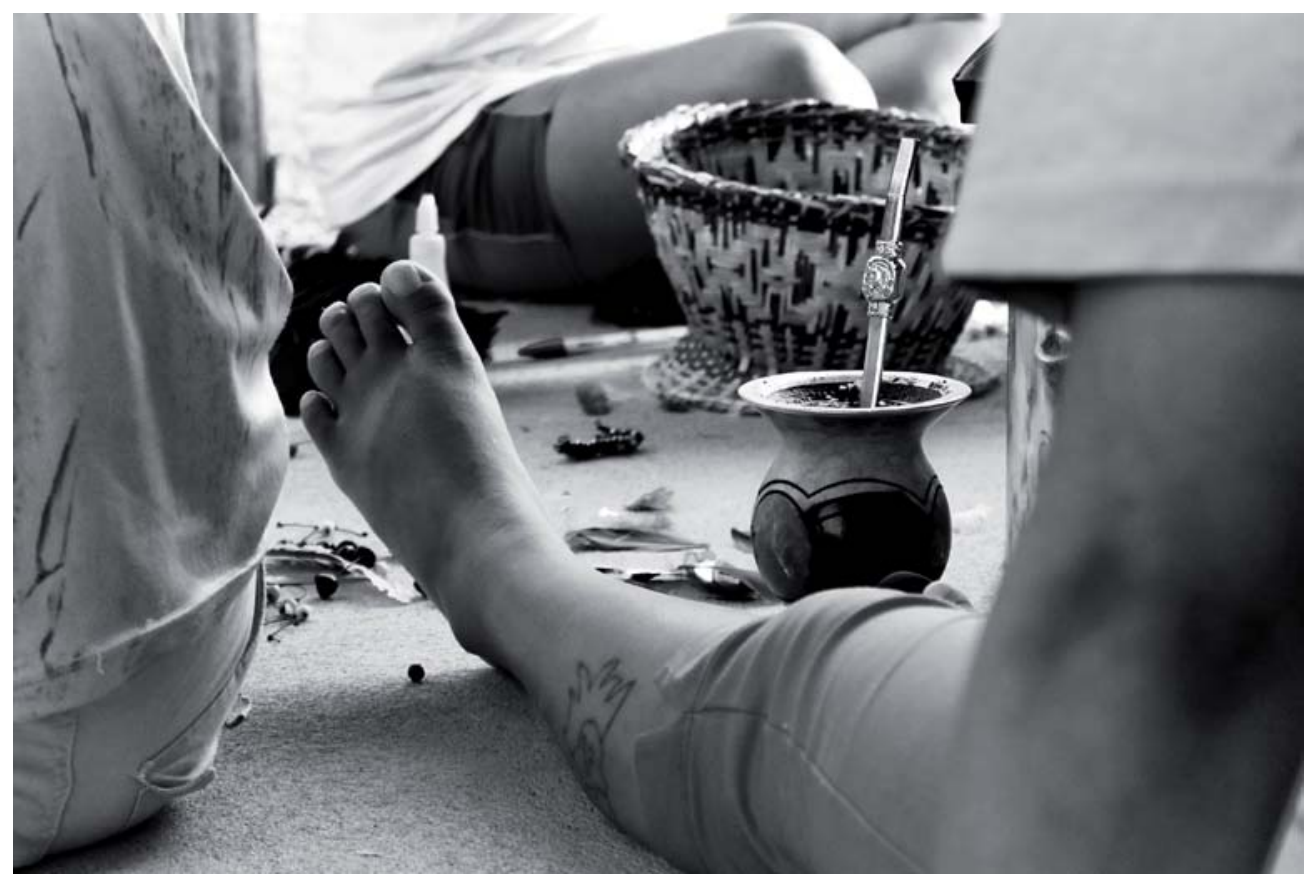

Figura 7: Mujeres del grupo trabajando en la producción de la artesanía. En el detalle, el mate, té típico guaraní (marzo de 2009). 
Con este caso queremos mostrar cómo la pertenencia a la etnia fue adaptándose a la realidad del grupo. Nos encontramos ante una formación híbrida donde caben las dos formas posibles de identificación, una tradicional, transmitida de padres a hijos, y otra más subjetiva, que se inserta en el campo de la autoidentificación. Las dos formas de inclusión son válidas para la comunidad (Figura 5).

Siguiendo por este camino, podemos ver cómo la identidad juega con la inclusión/ exclusión de los miembros. Esta puede ser benéfica o perjudicial, tanto en el ámbito interno del grupo como en el externo. Los matrimonios entre indígenas y no indígenas, o entre indígenas de distintas etnias, pueden llegar a causar problemas para determinados grupos y miembros. En Kakané Porã no existe ningún tipo de restricción formalizada en relación a los matrimonios de los miembros de la comunidad. Tuve una larga conversación sobre el tema con un pequeño grupo kaingang en la aldea. Lo que se valora al fin y al cabo es la felicidad encontrada en el matrimonio. En general, los valores vistos en relación a este tema son muy cercanos a los valores encontrados en la sociedad amplia: los valores occidentales guiados por la búsqueda de la pareja ideal e indisoluble.

Durante la misma conversación surgió el tema del pasado. El grupo me dijo que antiguamente las cosas no eran así, que los kaingang se casaban con los kaingang, y más aún, que un Kamé tenía que buscar un Kairú para casarse ${ }^{5}$. Estas cuestiones míticas parecen estar un poco alejadas de la realidad actual de gran parte de los indígenas kaingang de Kakané Porã, pero algunos de sus miembros siguen viviendo «de acuerdo con la tradición», como ellos mismos dicen, lo cual es valorado de forma positiva en cierta medida. Durante nuestra conversación surgió el ejemplo de Setembrino, uno de los miembros de la comunidad. Según el grupo, Setembrino es un indígena que está más cerca de la tradición que otros: enseña y habla el idioma kaingang a sus hijos, algo bien visto por el grupo que formaba parte de la conversación. A la vez, el mismo grupo me comenta que, si dependiera de Setembrino, sus hijos se casarían con indígenas kaingang de sus mitades opuestas, lo que generó una discusión sobre el derecho de este tipo de interferencia en la vida de los niños (Figura 6).

$\mathrm{Al}$ igual que los matrimonios, el idioma también puede jugar un papel determinante en la inclusión o exclusión de los miembros. Hoy en día la lengua propia es muy valorada y se lleva en consideración para determinar, entre ellos mismos, quién es indígena, $\mathrm{y}$, también, qué tipo de indígena es.

En entrevista, Valdinei ejemplifica muy bien esta relación con la lengua. Cuando le pregunto si habla en idioma kaingang me contesta así:

«Poco, algunas palabras, pero lo entiendo. Es un error de nuestros padres, ellos ya no nos enseñaron mucho. Yo fui a la escuela y aprendí normal [en portugués], a leer libros, estudiar (...) Como todos; normal. Lo que creo que no está bien, porque allí en Marrecas, la aldea de Jovina, hay enseñanza en kaingang, lo que debería haber aquí, una escuela dentro de la aldea con una profesora kaingang, una de guaraní y otra de portugués, para que podamos aprender a hablar en las dos lenguas. Es necesario, es nuestra lengua, ¿no? Es importante saber la lengua, pues si no sabes te dicen que no eres indígena, que no

${ }^{5}$ Las dos mitades se complementan en el matrimonio cuando una persona de una mitad se casa con otra de la otra mitad, y esta es una de las formas de mantener el equilibrio cósmico del universo kaingang. 


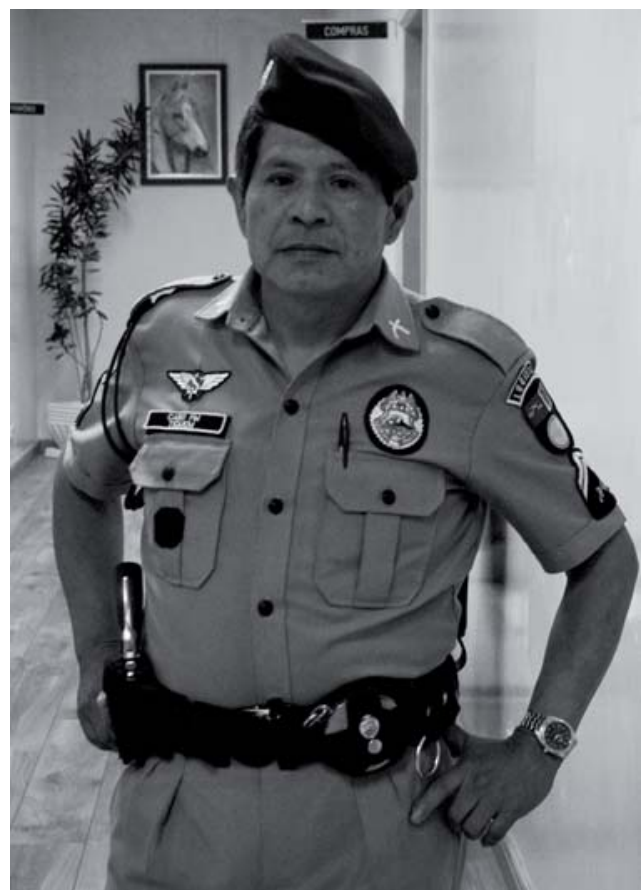

Figura 8: Tiquen, indígena xetá, perteneciente al cuerpo de policía de Paraná (octubre de 2009).

sabes, que no hablas, entre los propios indígenas incluso. Por ejemplo, hay algunos que vienen de lejos, de Marrecas, Rio das Cobras, que hablan muy poco en portugués (...). Eso no es culpa mía, mi padre y mis tíos sabían hablar en kaingang, pero, en mi casa normalmente hablábamos en portugués, porque mi abuelo creía que nosotros teníamos que saber hablar bien con las personas, y él fue uno de los que pagó a una persona de fuera para que viniera a enseñar a todos mis tíos y tías. Todos ellos saben leer y escribir, ninguno es licenciado, pero tampoco ninguno es analfabeto. Mi padre creía que era importante saber leer y escribir, y todos aprendieron».

De esta forma podemos ver los cambios que se han producido en cuanto a la valoración del propio idioma: pasamos de un momento en el que el portugués tenía valor y el idioma indígena no, a la valorización del idioma ancestral como forma de identificación y jerarquía entre indígenas.

Podemos observar así que la identidad tiene un papel crucial en la vida cotidiana de estos grupos indígenas, que puede influir en el grado de inserción dentro del propio grupo o en las demás áreas indígena de la misma etnia.

\section{Inmigración}

La inmigración es sin duda una de las cuestiones sociales más comentadas hoy en día en todo el mundo. La reflexión sobre el tema aparece diseminada en los más diversos espacios de la vida social y medios de comunicación de masas. 
En la actualidad, una parte considerable de la discusión en relación a los procesos migratorios sigue girando en torno a las migraciones internacionales. La avalancha de trabajadores extranjeros que se desplazaron y siguen desplazándose en dirección a los actuales centros receptores, ocupa gran parte del imaginario social diseminado hoy en día sobre el tema de las migraciones. Pero cuando hablamos del proceso migratorio ocurrido en la comunidad estudiada, nos referimos a una migración interna. La migración interna en Brasil fue y es una importante característica de esta sociedad.

En la realidad específica de la aldea Kakané Porã, el mercado de trabajo encontrado en la ciudad de Curitiba es uno de los principales motivadores de los desplazamientos, aunque, como veremos, no fue la única motivación para que los miembros de la comunidad decidieran migrar a la ciudad (Figura 7).

Vemos también la importancia de las redes sociales y de las relaciones de parentesco para el mantenimiento de la comunidad y la incorporación de nuevos miembros. Podemos conglomerar estas relaciones bajo la nomenclatura de redes migratorias.

Las redes migratorias son un aparato de apoyo que los inmigrantes utilizan como forma de facilitar el ingreso en el nuevo país/región, o de minimizar los traumas que puedan surgir en los primeros contactos con la sociedad de acogida. No existe un modelo preestablecido ni tampoco formas rígidas que identifiquen las redes como tales. Éstas pueden asumir distintos formatos, adaptándose a las realidades específicas de cada situación. Para explicar mejor el concepto podemos ver cómo García Martínez recoge la concepción de Lomnitz sobre las redes:

«un conjunto estructurado de relaciones sociales entre individuos. Es un concepto descriptivo de carácter abstracto afín al concepto de 'campo' en física. Un campo es un espacio asociado a alguna variable física de manera tal que cada punto del espacio está asociado a un valor de la variable (...). La variable subyacente a una red podría ser casi cualquier variable social» (Lomnitz, citado por García Martínez 2006: 243).

Las redes están basadas en relaciones de amistad, parentesco y/o comunidad, y establecen una forma concisa de relación entre el país/región de origen y la sociedad de acogida. Los estudios desarrollados alrededor de las redes migratorias intentan demostrar que éstas son enormemente relevantes para las migraciones y que van más allá de las explicaciones centradas exclusivamente en los grandes motivadores económicos.

Entre los pueblos indígenas, las relaciones de parentesco y amistad permiten en gran medida el movimiento aldea/ciudad y ciudad/aldea, práctica habitual entre algunas de estas comunidades, garantizando la seguridad necesaria para este tránsito.

Constatamos la importancia de las redes migratorias cuando hablamos del gran contingente indígena en la ciudad de São Paulo, en concreto de los Pankararu que viven en la zona sur de la ciudad, en la «Favela Real Parque», y en otros barrios periféricos. Son aproximadamente 2.500 personas, de las cuales unas 1.500 se concentran en dicha favela, constituyendo el mayor contingente de esta etnia. La inmigración de este pueblo comenzó en la década de 1940, siguiendo, de alguna forma, el flujo migratorio que llevó a un elevado número de trabajadores nordestinos al sur del país ${ }^{6}$.

6 Los Pankararu son originarios del Estado de Pernambuco, en el nordeste brasileño. Además del 
Como el resto de inmigrantes, a su llegada los hombres trabajaron en la construcción civil, mientras que las mujeres se dedicaban principalmente al servicio doméstico. $\mathrm{Al}$ principio las estancias no eran definitivas y eran en su gran mayoría hombres los que iban a trabajar. Sólo a partir de la segunda generación se consolidaron unas bases sólidas que permitieron y permiten la instalación de nuevos miembros en el espacio urbano (Silva Lima 2008). Estas bases sólidas a las que nos referimos pueden entenderse dentro del concepto que estamos manejando de las redes migratorias. Estas familias que acabaron arraigándose en la ciudad constituyen una red clave para aquellos que a lo largo de los años han migrado, de forma definitiva o no, a la ciudad (Figura 8).

En definitiva, los pueblos indígenas en sus desplazamientos internos utilizan las redes sociales para minimizar los costes de las migraciones. El apoyo y acogida de los miembros ya establecidos en los centros urbanos es un diferencial importante para que el proceso migratorio sea una experiencia exitosa.

Incluimos a continuación las historias de vida de cuatro de los miembros de la comunidad que nos servirán para elucidar sobre los puntos de los que hemos hablado anteriormente: las razones que llevaron a las personas de la comunidad a migrar a la ciudad de Curitiba y la importancia de las redes migratorias tanto en la toma de decisión de migrar como en la llegada a la ciudad.

\section{Historias de vida}

\section{Tuki}

Tuki, indígena kaingang, nació en la aldea de Xanxerê, tierra indígena de Xapecó, próxima al municipio del mismo nombre en Santa Catarina. Tiene treinta y seis años. Se trasladó a la aldea Mangueirinha con siete años y allí pasó gran parte de su vida.

En el caso de Tuki la cuestión económica fue el principal motivo para que él y su esposa Rosângela dejasen su aldea original y viniesen a Curitiba. En Mangueirinha trabajaba básicamente en la agricultura, actividad de la que gran parte de las familias de las «aldeas grandes» sacan su sustento.

No hace mucho tiempo que vino a la ciudad, aproximadamente un año. El principal motivo del cambio fueron las oportunidades de trabajo ofrecidas en la urbe.

Nada más llegar estuvo empleado en una empresa metalúrgica que produce fogones a gas y a leña. Tuvo que dejar el trabajo porque fue a vivir a la aldea Cambuhy. Cuando llegó a Curitiba, Tuki no fue a vivir allí directamente. Estuvo una temporada en la casa de su hermano que vive en São José dos Pinhais, zona metropolitana de Curitiba, puesto que en Cambuhy había que encontrar un lugar para él y su familia. Cuando Carlos, el cacique del grupo, organizó la que sería su casa en la aldea antigua, éstos pudieron hacer la mudanza.

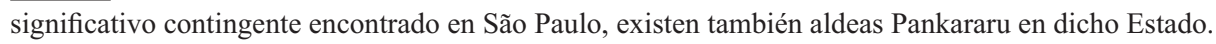


Una vez en la aldea Cambuhy, encontró trabajo en una fábrica en las afueras de la ciudad, donde permaneció cuatro meses. En 2008, justo después de la mudanza de la comunidad a Kakané Porã, encontró empleo en una fábrica de ladrillos prefabricados. La fábrica está al otro lado de la calle de la aldea, y otros indígenas de la comunidad también encontraron trabajo allí.

Tuki conocía a gran parte de los indígenas que estaban en Cambuhy, ya que muchos de ellos son de Mangueirinha. Nos deja claro que, además del apoyo de su hermano, tuvo el de Carlos que acomodó a su familia en la aldea lo más rápido que pudo. Esta relación previa con la comunidad facilitó su establecimiento en la ciudad.

La renta familiar procede principalmente del trabajo de Tuki en la fábrica de ladri1 los, alrededor de mil reales (más o menos 300 euros). Sacan algo de la artesanía pero, por el momento, la parte significativa de los rendimientos gira en torno a su trabajo en la industria.

\section{Tuxaua}

La trayectoria de Tuxaua en los centros urbanos es mucho más larga. Sale de su aldea aún joven y sigue el camino hacia los centros urbanos motivado principalmente por la búsqueda de mejores condiciones de vida.

Tuxaua tiene alrededor de 40 años, y es indígena guaraní del litoral de São Paulo. Nos cuenta que sus padres también son inmigrantes: su madre es indígena paraguaya y su padre nació en el Estado del Mato Grosso do Sul. Creció en la aldea Bananal, ciudad de Peruíbe, al sur de Santos, importante ciudad del litoral paulista por su puerto.

A los trece años salió de la aldea. Desde muy pronto, incluso antes de salir de ella, viajaba con su hermano, que fue el responsable de su «haber caído en la carretera», como llama él mismo a su vida viajera. Los viajes y visitas a otras aldeas son bastante comunes para su grupo. Su primer desplazamiento importante fue en dirección a la ciudad de São Paulo. Allí trabajaba con su hermano vendiendo yerbas medicinales en las calles del centro.

Permaneció viajando entre la capital y la aldea hasta los 20 o 21 años. Tras este período de 7 u 8 años en São Paulo vendiendo medicinas empieza a trabajar casi exclusivamente con artesanía. En el momento en el que empezó a dedicar más esfuerzos a esta actividad comenzó a viajar más constantemente. De São Paulo se fue a la ciudad de Río de Janeiro, donde se estableció, sin dejar por ello de salir a trabajar también a otras ciudades del litoral de ese Estado. Volvió a São Paulo, y luego se marchó a Mato Grosso do Sul. Allí circuló por algunas ciudades y aldeas, siempre trabajando con artesanía. De esta forma, estuvo desplazándose durante algunos años por esta zona del país, pero siempre mantuvo como lugar de referencia su aldea. Allí, en Bananal, surgió la posibilidad de venir a Curitiba. Conocía ya a Alcindo, que le invita a venir a la ciudad.

Alcindo y su familia, que forman parte del grupo de la aldea curitibana desde su surgimiento, normalmente viajan durante los veranos vendiendo artesanía, y sus 
destinos principales son el Estado de Santa Catarina, al sur, o el litoral de São Paulo y Rio de Janeiro, al norte. El motivo de estos cortos desplazamientos es el buen tiempo y el consecuente crecimiento del turismo en estas zonas. En uno de estos viajes Tuxaua y Alcindo se conocen y en un momento posterior surge la invitación. Tuxaua me comenta: «Curitiba era la única ciudad que aún no conocía bien, sabía que hacía mucho frío y poco más». Vino a Curitiba en 2006, cuando la comunidad estaba asentada en la aldea Cambuhy, $y$, al igual que él, otros indígenas fueron invitados o encontraron las puertas de la comunidad abiertas. Es otra muestra de la importancia de esta red de comunicación generada por los lazos de amistad que en su momento facilita los desplazamientos. «Los indígenas son muy viajeros, en un momento están aquí, otro allí y otro más allá. El indígena tiene su casa pero no tiene parada».

Según Tuxaua, el factor económico es uno de los principales motivadores para que los indígenas migren a los centros urbanos. Pero a la vez nos coloca otro punto que debe tenerse en cuenta. Incluso viviendo en las aldeas, las comunidades indígenas, principalmente las del sur, están cercadas por la sociedad nacional, y en muchos sentidos existen niveles de interacción y dependencia en relación a esta. Uno de los motivadores, según Tuxaua, para el movimiento aldea/ciudad, es también la curiosidad de conocer las ciudades grandes.

\section{Rivelino}

Como hemos dicho, el proceso migratorio puede tener muchas motivaciones. $\mathrm{Al}$ acercarnos al caso de Rivelino y su familia encontramos una causa que va mucho más allá del factor económico. Rivelino y su familia son de la aldea indígena de Palmeirinha, una aldea guaraní localizada dentro de la aldea de Mangueirinha en Paraná. Salieron de su aldea principalmente por motivos políticos generados por el cambio de líderes.

Rivelino, mbyá guaraní, es una figura de referencia en la aldea Kakané Porã en los días de hoy, de la misma forma que lo fue también en Palmerinha. Allí ejerció de cacique durante más o menos doce años.

Él y su familia están en Curitiba desde 2005. Salieron de la aldea de Palmerinha, como dije, por motivaciones políticas. Nos cuenta Rivelino que antes de venir ya no tenía muchos parientes en su aldea. El apoyo de los familiares, junto a la labor realizada por el cacique, son una fuerte base para la manutención del puesto. Además, nuevos miembros llegaron a la comunidad, y éstos empezaron a no estar de acuerdo con el trabajo realizado por Rivelino. El puesto de cacique conlleva una insignia de poder, sobre todo de poder político, y por ello es un puesto que puede ser deseado por algunos miembros del grupo.

Rivelino dejó el puesto de cacique por voluntad propia. Los líderes indígenas en general intentan trabajar de acuerdo con el sentido común y la sensatez, y, cuando sienten que la comunidad ya no está satisfecha con su trabajo, lo más consecuente para ellos es dejar el puesto. Eso fue lo que ocurrió en su caso. 
Cuando salió de Palmerinha se dirigió a Piraquara, ciudad vecina de Curitiba que cuenta con una importante aldea guaraní. Allí viven parte de sus parientes. Estuvo viviendo por allí un par de meses, y fue entonces cuando se encontró con Carlos, el cacique de Kakané Porã, que le invitó a que fuera a vivir con su familia en la comunidad. Consciente de la importancia de Rivelino en Palmerinha y de la seriedad de su trabajo, Carlos le pidió que se instalase en la aldea para fortalecer políticamente la lucha que estaban emprendiendo en busca de la nueva área. Rivelino, que conoce a Carlos desde hace años, no dudó en venir a Cambuhy, para de esta forma poder ayudar al cacique en lo que pudiera. Junto a él vinieron los otros guaraníes que hoy viven en Kakané Porã.

Rivelino y su familia también sacan el sustento básicamente de la venta de artesanía. Nos habla de la posibilidad de trabajar fuera de la aldea, principalmente en la construcción. Él mismo, en algunos momentos, estuvo trabajando en las obras que están alrededor de la aldea.

Vivir en la ciudad no es su objetivo a largo plazo. Rivelino y Elza tienen hijos pequeños, y su mayor preocupación es que cuando estos se hagan un pocos más mayores quieran apegarse a las costumbres no indígenas, dejando así su cultura y tradiciones de lado. En las «aldeas grandes» es más fácil que los niños tengan un contacto mayor con la tradición guaraní. Por eso no pretenden quedarse en la ciudad por mucho tiempo, porque para ellos es fundamental que los niños crezcan en una aldea más cercana a la tradición indígena, que puedan vivenciar de forma más intensa y cotidiana el modo de ser guaraní. Hoy, cuando tienen que participar en algún ritual o liturgia, tienen que irse a Piraquara, ya que en Kakané Porã no tienen una Casa de Reza ni chamán, dos elementos fundamentales en el cotidiano guaraní. Les preocupa que un día, cuando los niños quieran volver a las otras aldeas, no sean aceptados. Les da miedo que en algún momento se les discrimine por haber crecido en la ciudad, que pierdan su lengua y sus costumbres: «Si nosotros nos quedamos aquí mis niños no aprenderán a plantar la mandioca, o el maíz, el maíz sagrado que nosotros tenemos, los cacahuetes, la patata dulce... Y cuando vuelvan a la aldea grande van a sufrir».

Aun así, cree que ha valido la pena venir a Curitiba. Sabe que su llegada fue importante para el grupo en la conquista de la aldea indígena: «Me siento victorioso porque les ayudé a conseguir su espacio, su casa». Al igual que fue estratégica la relación anterior que él tenía con Carlos y la intención de ayudar en la lucha por la tierra, también lo fue para que las otras familias guaraní pudiesen venir y establecerse en Curitiba. Es decir, estas relaciones cercanas, sean lazos de amistad o de parentesco, fueron de gran importancia o quizás el principal motivador para que las familias guaraní que hoy viven en Kakané Porã pudiesen asentarse en la ciudad.

\section{Moisés}

Al igual que Rivelino y su familia, Moisés (kaingang) tampoco emigró por las oportunidades de trabajo. Moisés nació en la aldea indígena Bananeiras, en el municipio de Nonoai (Rio Grande do Sul). Curitiba se cruza en su camino tras aprobar 
la selectividad para el acceso a la Licenciatura de Enfermería en la Universidad Federal de Paraná. Es entonces cuando viene a vivir a la ciudad.

No conocía Curitiba, y su primer contacto se produjo al instalarse en una residencia de estudiantes de la universidad. Tenía una beca de estudios de la $\mathrm{FUNAI}^{7}$ que le permitía pagar la residencia y mantenerse en Curitiba, y de forma paralela seguía produciendo y vendiendo artesanía para complementar su renta.

Estuvo viviendo en la residencia estudiantil durante seis meses. Luego conoció a Carlos en la Plaza Osório, punto estratégico del centro donde los indígenas de la ciudad montan las mesas de artesanía durante la semana. Carlos le dijo que la aldea Cambuhy tenía las puertas abiertas si quería ir a vivir allí.

Al igual que otros indígenas de la aldea, Moisés nos cuenta que en Curitiba es posible vivir de la venta de artesanía. Cuando le pregunto si la vida laboral en la ciudad es más atractiva o más amplia que en las aldeas, me contesta que no exactamente, que en algunas de la «aldeas grandes» se puede vivir perfectamente del trabajo en el campo, y que depende mucho de cómo quieras vivir y de las necesidades que tengas. Según Moisés, allí se vive de forma más simple y tranquila, sin grandes lujos, pero se vive bien. Al igual que Tuxaua, Moisés considera el venir a la ciudad como una búsqueda, lo encara como una experiencia que puede ser mejor o peor, ya que de hecho algunos consiguen adaptarse bien y otros pueden no llegar a hacerlo. Muchos de los indígenas vienen a probar suerte.

Para él vivir en la ciudad tiene un lado bueno, y es que cuando se está fuera de la aldea se aprende a sobrevivir de otras formas, se empieza a trabajar en otras cosas diferentes al trabajo del campo o de la artesanía. Pero Moisés nos cuenta que tuvo muchos problemas de adaptación al principio: «La ciudad es muy difícil, si no hubiese ido a Cambuhy probablemente hubiera vuelto a la aldea».

\section{Conclusiones}

El tema de los pueblos indígenas en espacios urbanos incorpora una serie de cuestiones fundamentales que hemos intentado tratar a lo largo del texto. Tiene una relación directa con los fenómenos de la modernidad, entre ellos, con la amplia temática de la globalización, así como con los intereses políticos y económicos de los países y zonas donde tales pueblos se encuentran.

Al acercarnos al tema del territorio, vimos que éste es un elemento de gran relevancia para la manutención de los grupos indígenas, y que fue el que desencadenó el propio surgimiento del núcleo base del grupo y, posteriormente, de lo que conocemos hoy en día como la comunidad de Kakané Porã. El cacique Carlos fue desde el comienzo el principal elemento congregador. De él surgió la iniciativa de buscar a los indígenas que estaban viviendo en la ciudad en el momento del surgimiento del grupo.

\footnotetext{
7 Fundación Nacional del Indígena, órgano estatal que gestiona las cuestiones indígenas en Brasil.
} 
Constatamos también que la identidad es un importante elemento de manutención étnica en el grupo, que está presente en el día a día de la comunidad. Sirve de guía para la vida de la comunidad y todo, en algún momento, se relaciona con la necesidad de afirmación de ésta. Se trata de una forma de relacionarse con el mundo, de interacción tanto dentro como fuera de la aldea.

Como se puede observar a lo largo del texto, la identidad en la comunidad específica tiene muchas sutilezas. En los discursos encontramos una autoafirmación que nos lleva a pensar que en ningún momento existen dudas por parte de los indígenas en relación a su etnicidad. A la vez, vemos que ese discurso puede ser contradictorio cuando observamos su día a día. El grupo está pasando por un proceso de construcción de una identidad híbrida donde cabe todo, incluidas las propias contradicciones inherentes a la modernidad.

Se ha hablado también de las motivaciones que trajeron a una buena parte de la población de otras áreas indígenas a la ciudad de Curitiba. Gran parte de los miembros de la comunidad decidieron venir a la ciudad movidos por las ofertas de empleo y la perspectiva de mejora del nivel de vida. La salida de las aldeas de origen está motivada por la aparente falta de sostenibilidad de la vida en el campo. El venir al centro urbano supone así una ampliación de las salidas laborales.

En el texto se ha intentado dejar claro que la relación entre inmigración y economía existe, pero que sería incompleto explicar y reducir el fenómeno a este único factor. De esta forma, intentamos analizar otras motivaciones que trajeron a algunos miembros de Kakané Porã a Curitiba.

Otra cuestión analizada es la importancia de las redes migratorias. Para elucidar mejor sobre este tema, retomo otra vez el caso de Rivelino. Su llegada a Curitiba atrajo a las demás familias guaraní que hoy están viviendo en la aldea. De igual forma, la figura del cacique Carlos también fue de gran importancia para el crecimiento de la comunidad y para la incorporación de nuevos miembros. De esta forma, es un importante apoyo, quizás el más relevante, para las familias que decidieron migrar a Curitiba.

Vemos que los tres temas principales trabajados en la investigación tienen una relación directa. Es casi imposible separar la identidad de la territorialidad, de igual forma que es complicado separar la inmigración de las cuestiones relacionadas con la tierra. Es decir, no tiene sentido ver la comunidad de Kakané Porã por compartimentos estanco. Debemos tener en consideración distintos factores y puntos de vista al analizar tanto la temática general como el grupo específico, ya que no pueden entenderse si son analizados desde aspectos y ópticas fragmentadas y desconectadas. La complejidad de matices y la interconexión de distintos aspectos es una característica inherente a las sociedades complejas, y por lo tanto, a la aldea Kakané Porã.

A través del análisis de estos temas, los pueblos indígenas, la identidad, la territorialidad, la inmigración y el espacio urbano, hemos intentado realizar un abordaje contemporáneo sobre una significativa realidad social. Consideramos que este es un tema de gran relevancia, dado que es un fenómeno cada vez más común en Latinoamérica, por lo que los investigadores deben prestarle la debida atención para intentar comprender esa nueva realidad y poder actuar adecuadamente a partir de ella. 


\section{Referencias bibliográficas}

AgIER, Michel

2001 «Distúrbios identitários em tempos de globalização». Mana 7 (2): 7-33.

Baptista Da Silva, Sergio

2002 «Dualismo e Cosmologia Kaingang: O Xamã e o Domínio da Floresta». Horizontes Antropológicos 18: 189-209.

Calavia SÁez, Oscar

2007 «La postmodernidad indígena y sus disonancias. Los límites del multiculturalismo en el Brasil». Amérique Latine Histoire et Mémoire 13: 1-9.

CARdoso de Oliveira, Roberto

1976 Identidade etnia e estrutura social. São Paulo: Pioneira.

Castells, Manuel

2000 O poder da identidade. São Paulo: Paz e Terra.

ESPINOSA DE RIVERO, Oscar

2009 «Ciudad e identidad cultural ¿Cómo se relacionan con lo urbano los indígenas amazónicos peruanos en el siglo XXI?». Bulletin de l'Institut Français d'Etudes Andines 38: 47-59.

FíGOLI, Leonardo H. G. y Dimitri FAzito

2009 «Redes sociales en una investigación de migración indígena: el caso de Manaus». Revista Brasileira de Estudos da População 26 (1): 77-95.

García CANClini, Néstor

2003 Culturas Híbridas. São Paulo: EDUSP.

García Hierro, Pedro

2001 «Territorios indígenas: tocando las puertas del derecho». Revista de Indias 223: 619-647.

García Martínez, José Alfonso

2006 «Migraciones, inserción laboral e integración social». Revista de Economía Mundial 14: 231-249.

LADEIRA, Maria Inês

2007 O Caminha Sob a Luz. São Paulo: UNESP.

SiLva Lima, Carmen Lucia

2008 «Vivendo na metrópole: os Pankararu em São Paulo», en Actas de la $26^{a}$ Reunión de la Asociación Brasileña de Antropología, (Porto Seguro 1-4 de junio de 2008). Documento electrónico, <http://www.abant.org.br/news/show/id/12>, con acceso el $27 / 05 / 2011$.

Stavenhagen, Rodolfo

2002 «Identidad indígena y multiculturalidad en América Latina». Araucaria 7: 13-22.

Ximenes Ponte, Laura Alene Saré

2009 «A população indígena da cidade de Belém, Pará: alguns modos de sociabilidade». Boletim do Museu Paraense Emílio Goeldi 4 (2): 261-275. 